\title{
Material and Ultrafast Optoelectronic Properties of Furnace-Annealed Arsenic-Ion-Implanted GaAs
}

\author{
Gong-Ru Lin, Member, IEEE, Wen-Chung Chen, C.-S. Chang, Shyh-Chin Chao, \\ Kaung-Hsiung $\mathrm{Wu}, \mathrm{T}$. M. Hsu, W. C. Lee, and Ci-Ling Pan, Member, IEEE
}

\begin{abstract}
Structural, electrical, and ultrafast optical properties of furnace-annealed arsenic-ion-implanted GaAs (GaAs : $\mathrm{As}^{+}$) has been investigated for its applications in ultrafast optoelectronics. From these studies, we determine that GaAs substrates implanted with $200-\mathrm{keV}$ arsenic ions at $10^{16}$ ions $/ \mathrm{cm}^{2}$ and furnaceannealed at $500{ }^{\circ} \mathrm{C}-600{ }^{\circ} \mathrm{C}$ would have recovered its crystallinity, be highly resistive, and exhibit picosecond photo-excited carrier lifetimes. The duration of the electrical pulses generated by photoconductive switches (PCS's) fabricated on the optimized material was $\approx 4 \mathrm{ps}$. The risetime $(10 \%-90 \%)$ and $1 / \mathrm{e}$ falltime were, respectively, $\approx 2$ and 3 ps. These results were measurementsystem limited. We estimated the actual response to be $\approx 2 \mathrm{ps}$, consistent with a photo-excited carrier lifetime of $\approx 1.8 \mathrm{ps}$. The peak responsivity was $\geq 4 \times 10^{-3} \mathrm{~A} / \mathrm{W}$. The dark current for the GaAs : $\mathrm{As}^{+}$PCS biased at $40 \mathrm{~V}$ was as low as $5 \mathrm{nA}$. The break down field was higher than $150 \mathrm{kV} / \mathrm{cm}$. These characteristics are comparable to those of state-of-the-art photoconductors such as LT-GaAs.
\end{abstract}

Index Terms - Arsenic-ion-implanted GaAs, photoconductive switch, ultrafast optoelectronics.

\section{INTRODUCTION}

$\mathbf{P}$ HOTOCONDUCTORS with ultrashort photo-excited carrier lifetime, good optical responsivity, high breakdown field, and low dark current are essential for ultrafast optoelectronic switching applications. Various classes of semiconductors, e.g., intrinsic, impurity-dominated, radiation-damaged, polycrystalline, and amorphous, have been explored as ultrafast photoconductors [1]. In particular, the ion implantation technique has been employed extensively [2]-[5]. Carrier lifetimes as short as $0.5-0.6$ ps have been reported as the saturation limit for GaAs samples irradiated by protons $\left(\mathrm{H}^{+}\right)$[2]. Similar results were reported for oxygen-ionimplanted silicon-on-sapphire (SOS) materials [5]. On the other hand, nonstoichiometric arsenic-rich GaAs grown by molecular beam epitaxy (MBE) at low substrate tempera-

Manuscript received September 8, 1997; revised April 8, 1998. This work was supported in part by the National Science Council (NSC) of the Republic of China under Grant NSC84-0212-M009-002 and Grant 84-2215-E-009-092.

G.-R. Lin is with the Institute of Electro-Optical Engineering, Tatung Institute of Technology, Taipei 104, Taiwan, ROC.

W.-C. Chen, C.-S. Chang, and C.-L. Pan are with the Institute of ElectroOptic Engineering, National Chiao Tung University, Hsinchu, Taiwan 30010, ROC.

S.-C. Chao and K. H. Wu are with the Department of Electro Physics, National Chiao Tung University, Hsinchu, Taiwan 30010, ROC.

T. M. Hsu and W. C. Lee are with the Department of Physics, National Central University, Chung-Li, 32054 Taiwan, R.O.C.

Publisher Item Identifier S 0018-9197(98)06386-6. ture (LT-GaAs) have been the subject of intensive studies [6]. It exhibited nearly ideal electrical and optoelectronic properties for ultrafast optoelectronic applications. Recently, a new class of arsenic-rich material, arsenic-ion-implanted GaAs or GaAs: $\mathrm{As}^{+}$, has emerged as a potential alternative to LT-GaAs [7]. The structural and electrical characteristics of LT-GaAs and GaAs: $\mathrm{As}^{+}$have been shown to be quite similar [8], [9]. The ultrafast optical characteristics of the as-implanted arsenic-rich GaAs materials have been reported [10]-[12]. Subpicosecond carrier lifetimes were observed. However, as-implanted or as-grown nonstoichiometric GaAs obtained by using either the arsenic-ion-implantation or the LTMBE process suffer from the following: the crystallinity of the material is degraded [13], [14]. As a result, the carrier mobility is substantially lower [12], [15]. This also leads to a defect-dominated hopping conducting mechanism, which destroys the highly resistive nature of the original substrate [8], [15]. Consequently, the as-implanted GaAs : $\mathrm{As}^{+}$is not yet suitable for fabrication of ultrafast optoelectronic devices. To remedy this, rapid thermal annealing (RTA) has been successfully employed. The effects of RTA on photo-excited carrier lifetime and electrical properties of GaAs : $\mathrm{As}^{+}$were reported [16]. Ultrafast photoconductive switches were demonstrated on RTA-annealed GaAs: $\mathrm{As}^{+}$prepared by bombarding semiinsulating (SI) GaAs substrates with $200-\mathrm{keV}$ arsenic ions at the dosage of $10^{16}$ ions $/ \mathrm{cm}^{2}$ [10], [16]. We have also reported picosecond photoconductive switches fabricated on low-doseimplanted GaAs : As ${ }^{+}$[17]. An interesting alternative to RTA is furnace annealing. In this paper, we present a detailed study on the structural, electrical, and ultrafast optical properties of furnace-annealed $\mathrm{GaAs}: \mathrm{As}^{+}$. The optimum processing condition is determined to be furnace-annealing at $600{ }^{\circ} \mathrm{C}$ for $30 \mathrm{~min}$. Picosecond photoconductive switches (PCS's) were fabricated on this material. The devices exhibit characteristics better than or comparable to those of LT-GaAs.

\section{SAMPLE PREPARATION}

The substrates were liquid-encapsulated-Czochralski (LEC) grown SI GaAs wafers. For implantation of arsenic ions, we employ a commercial apparatus (Varian E220). The implanting dosage and energy were $10^{16}$ ions $/ \mathrm{cm}^{2}$ and $200 \mathrm{keV}$, respectively. Typical current density value was $1 \mathrm{~mA} / \mathrm{cm}^{2}$. The exposure time subject to the samples was 10-15 min. The postannealing process was performed $e x$ situ by the encapsulated thermal annealing technique. We used a quartz-tube 
furnace with flowing nitrogen gas. The annealing temperature was varied from $200{ }^{\circ} \mathrm{C}$ to $800{ }^{\circ} \mathrm{C}$. The annealing time was $30 \mathrm{~min}$.

\section{EXPERIMENTAL METHODS}

For structural characterizations of the arsenic-ion-implanted GaAs substrates, we employ double-crystal X-ray diffractometry (DCXRD) and transmission electron microscopy (TEM) techniques. In DCXRD, a standard GaAs crystal and a $\mathrm{Cu}_{\alpha}$ source were employed to check the crystallinity on (004) diffraction plane of the samples by measuring the rocking curve. For TEM analysis, the samples were carefully polished and ion-milled to reduce its thickness down to several nanometers. A JOEL model JEM-200CX electronic microscope with resolution of $2 \AA$ was utilized to obtain the cross-sectionalviewed photograph of bright field and associated diffraction matrix patterns. For dark current measurements, Schottky diodes with thermally evaporated gold $(0.5 \mu \mathrm{m}$ thick) contacts were fabricated on $\mathrm{GaAs}: \mathrm{As}^{+}$samples. Their current voltage $(I-V)$ characteristics were then measured by using an HP4145B semiconductor parametric analyzer.

For measurement of photo-excited carrier lifetime and transient index-of-refraction of the annealed samples, we employed a standard pump-probe setup [11], [18]. The light source was a home-made, passively mode-locked Ti : sapphire/HITCI laser [11]. It generated optical pulses at $82 \mathrm{MHz}$ with a pulsewidth of about $130 \mathrm{fs}$. The polarization and power ratio of pump and probe beams were parallel and $50 / 1$ in our experiment $(400 \mathrm{~mW} / 8 \mathrm{~mW})$. The laser wavelength was $0.865 \mu \mathrm{m}$, which corresponds to an energy of only about $13 \mathrm{meV}$ higher than the bandgap of GaAs $(1.42 \mathrm{eV})$. This wavelength was chosen to prevent either the intervalley scattering of the photo-excited carriers from the $\Gamma$ band to the satellite band (usually the $L$ band, $\Delta E_{\Gamma-L}=$ $300 \mathrm{meV}$ ) in $k$-space, or the emission of longitudinal optical phonon $\left(\Delta E_{\mathrm{LO}}=36 \mathrm{meV}\right)$. Thus the intraband relaxation and phonon scattering processes can be ignored in our experiments. The energy of the pump pulse mechanically chopped at 3.2 $\mathrm{kHz}$ was about $4 \pm 0.5 \mathrm{~nJ}$. This corresponds to an estimated injection density of photo-excited carriers of about $1 \times 10^{19}$ $\mathrm{cm}^{-3}$. The fractional change of the reflected probe beam was detected by a pair of large area $\mathrm{Si}$ p-i-n diodes operated in differential-detection mode and subsequently processed in a lock-in amplifier operated in a $(R, \theta)$ mode. The detection sensitivity of our system is usually better than $10^{-5}$. The transient change in reflectivity $\Delta R$ (in root mean square value) obtained from the lock-in amplifier was normalized to calculate fractional change in transient reflectivity, $\Delta R / R$. The transient refractive index change $\Delta n$ was evaluated by using the Simplified Kramers-Kronig relation [19], i.e., $\Delta R / R=4 \Delta n /\left(n^{2}-1\right)$.

The ultrafast switching response of the switch was examined by using an external electrooptic sampling (EEOS) system. The wavelength was set at $0.8 \mu \mathrm{m}$. The pump power incident on the PCS was $140 \mathrm{~mW}$ while the probe power was $5 \mathrm{~mW}$ or less. The reflective-mode electrooptic sampling module consists of a polarization beam splitter (PBS), a quarter- wave plate (QWP), a half-wave plate (HWP), and a $\mathrm{LiTaO}_{3}$ electrooptic probing crystal. The crystal was thinned and polished down to $60 \mu \mathrm{m}$ and placed upon the PCS. The probe point was about $2 \mathrm{~mm}$ away from the photoconductive gap. The temporal and spatial resolutions of the current system were estimated to be about 1 ps and $5 \mu \mathrm{m}$, respectively.

\section{Structural AND Electrical Properties}

\section{A. DCXRD Diffractometry}

The X-ray rocking curves for the as-implanted and annealed samples are shown in Fig. 1(a). The most significant side peaks at the lower angle side of the curves are attributed to the as-implanted layer. It is indicative of an expanded lattice constant for the implanted layer as compared with that of the SI GaAs substrate $(\mathrm{a}=5.6533 \AA$ ). The angular separation between principal and side peaks is about $240 \mathrm{arc} / \mathrm{s}$. By using the formula $t=\lambda \gamma_{H} /\left[\Delta \theta * \sin 2 \theta_{\mathrm{B}}\right]$, [20] we estimate the thickness of the as-implanted layer, $t \approx 90 \mathrm{~nm}$. In the formula, $\lambda$ is the X-ray wavelength, $\gamma_{H}$ is the direction cosine of the diffracted X-ray with respect to the surface normal, $\theta_{\mathrm{B}}$ is the Bragg's angle, and $\Delta \theta$ is the angular separation between adjacent maxima of the rocking curve. The thickness is in good agreement with results of TRIM simulation of the implantation profile. In general, the maximum deviation of the lattice constant $\Delta a$ and the vertical strain between the implanted region and the bulk $\Delta a / a$ can also be simply evaluated from the rocking curve by using the Bragg's law, $\Delta a / a=-\Delta \theta / \tan \theta_{\mathrm{B}}[21]$. A more accurate depth-dependent strain profile was obtained by fitting the X-ray rocking curves with calculated strain profiles. The latter was obtained by using a Phillips software package (HRD Simulation Software 1.0). The package is based on the usual kinematic theory for X-ray analysis [22]-[24]. The depth-dependent strain profile of the as-implanted GaAs: $\mathrm{As}^{+}$is shown in the inset of Fig. 1(b). The maximum vertical strain is $\Delta a / a 0.35 \%$ at a depth of about $0.09 \mu \mathrm{m}$ below the surface. In comparison, Fujioka et al. [25] reported a maximum lattice expansion of $0.36 \%$ for as-implanted GaAs : $\mathrm{As}^{+}$in a numerical study. Similar X-ray side peaks with an estimated lattice expansion of $0.0053 \AA$ was also observed in LT-GaAs grown at $200{ }^{\circ} \mathrm{C}$. The corresponding maximum strain is only $\Delta a / a=0.08 \sim 0.15 \%$ [26], [27].

After annealing, the X-ray sidepeak was observed to gradually shift toward the central peak. This leads to a slightly broadened and asymmetric central peak with a slowly decreasing tail toward the negative angular direction. For GaAs : $\mathrm{As}^{+}$ annealed at and above $T_{a}=500{ }^{\circ} \mathrm{C}$, the residual side peak essentially merged into the central peak. The asymmetry of the wings was less pronounced. For samples annealed at $T_{a}=$ $800{ }^{\circ} \mathrm{C}$, the $\mathrm{X}$-ray rocking curve is identical to that of SI GaAs. A very similar trend was observed in LT-GaAs [28]. The average vertical strain $(\Delta a / a)$ avg of $\mathrm{GaAs}: \mathrm{As}^{+}$annealed at different temperatures are shown in Fig. 1(b). These were obtained by integrating the strain profile over the implantation depth. Examining Fig. 1(a) and (b), we estimate that the critical annealing temperatures for the complete recovery of 


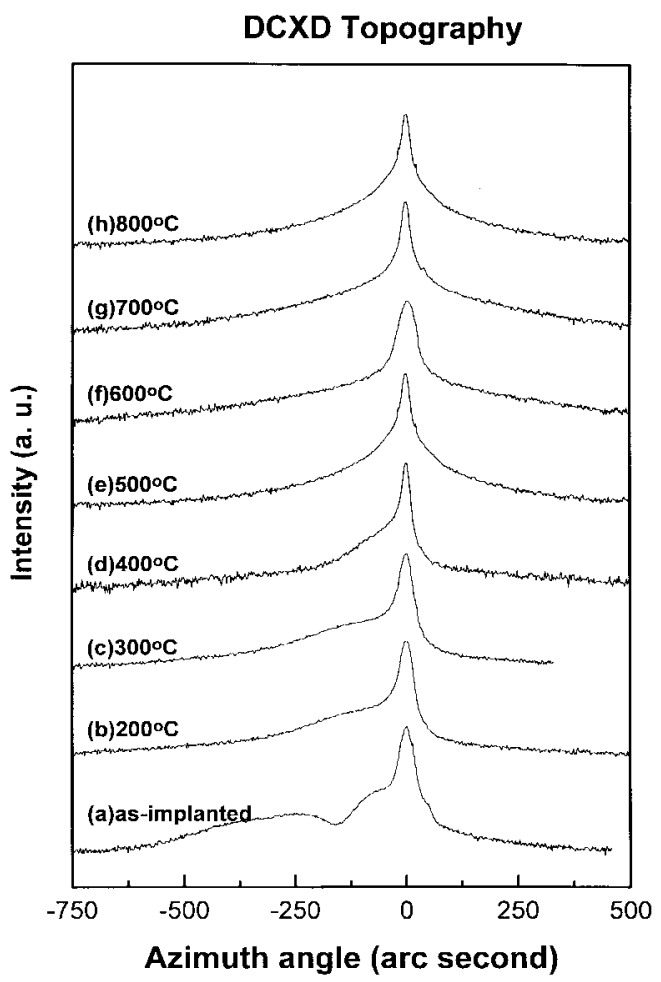

(a)

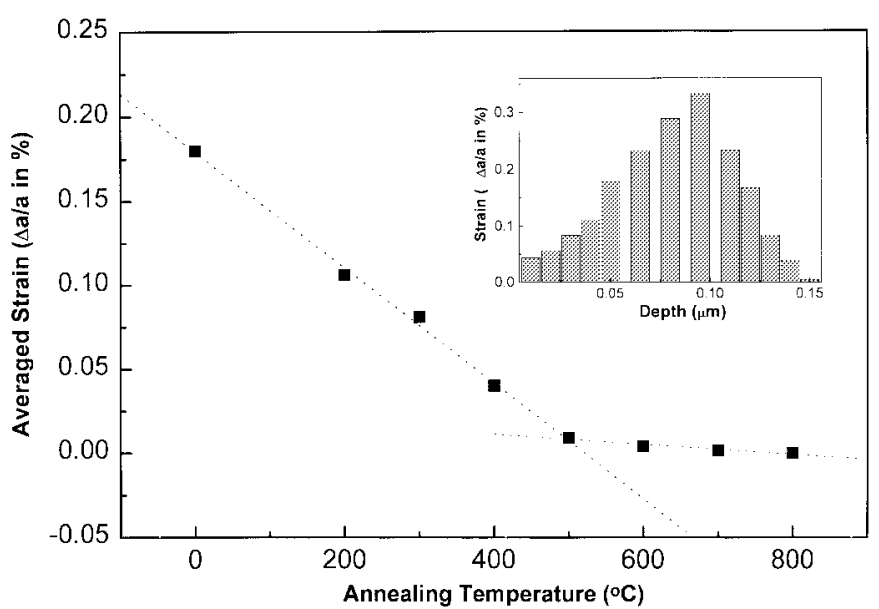

(b)

Fig. 1. (a) The double-crystal X-ray diffraction profiles of as-implanted and furnace-annealed GaAs: As $^{+}$samples. (b) The average vertical strain in the GaAs : $\mathrm{As}^{+}$samples are plotted as a function of annealing temperature. The inset shows the depth-dependent strain profile of as-implanted GaAs: $\mathrm{As}^{+}$.

crystallinity is $T_{a} \approx 500{ }^{\circ} \mathrm{C}$ as opposed to $T_{a}=450{ }^{\circ} \mathrm{C}$ for LT-GaAs [28].

The densities of the neutral $\mathrm{As}_{\mathrm{Ga}}$ antisite $\left(\left[\mathrm{As}_{\mathrm{Ga}}^{0}\right]\right)$ defects in GaAs: $\mathrm{As}^{+}$annealed at different temperatures can be evaluated from $(\Delta a / a)_{\text {avg. }}$. These are plotted as a function of $T_{a}$ in Fig. 2. The analysis is based on the following: it has been reported by several groups that three major kinds of defects- $\mathrm{As}_{\mathrm{Ga}}$ antisite (including $\mathrm{As}_{\mathrm{Ga}^{-}}^{0}$ and $\mathrm{As}_{\mathrm{Ga}}^{+}$ type defects), interstitial $\left(\mathrm{As}_{i}\right)$, and vacancy $\left(\mathrm{V}_{g a}\right)$ defects are present in LT-GaAs [29]-[32]. The concentration of the antisite defects is higher than the other kind of defects by at least one order of magnitude. Typically, $\mathrm{N}\left[\mathrm{V}_{\mathrm{Ga}}\right] \approx 3 \times 10^{17}$

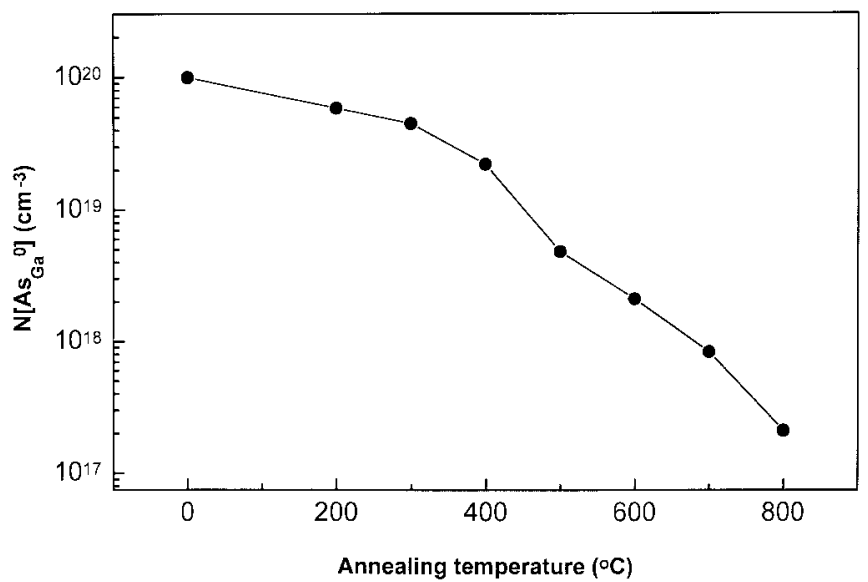

Fig. 2. The concentration of $\left[\mathrm{As}_{\mathrm{Ga}}^{0}\right]$ antisite defects in the GaAs: $\mathrm{As}^{+}$ samples plotted as a function of the annealing temperature.

$\mathrm{cm}^{-3}$ [29]. Furthermore, the concentration of $\mathrm{As}_{\mathrm{Ga}}^{0}$ defects, $\mathrm{N}\left[\mathrm{As}_{\mathrm{Ga}}^{0}\right] \approx 2-9.9 \times 10^{19} \mathrm{~cm}^{-3},[30],[31]$ is one order of magnitude higher than that of $\mathrm{As}_{\mathrm{Ga}}^{+}$defects, $\mathrm{N}\left[\mathrm{As}_{\mathrm{Ga}}^{+}\right] \approx$ $2-8 \times 10^{18} \mathrm{~cm}^{-3}$ [32]. Now the structural and electrical characteristics of GaAs : $\mathrm{As}^{+}$have been shown to be strikingly similar to that of LT-GaAs [33]. We thus argue that the $\mathrm{As}_{\mathrm{Ga}^{-}}^{0}$ type defects would also be the most dominant traps for carriers in GaAs: $\mathrm{As}^{+}$. Next, we assume that $\mathrm{N}\left[\mathrm{As}_{\mathrm{Ga}}^{0}\right]$ is linearly proportional to $(\Delta a / a)_{\text {avg }}$ in GaAs: $\mathrm{As}^{+}$. This is based on the empirical relation, $\mathrm{N}\left[\mathrm{As}_{\mathrm{Ga}}^{0}\right] \approx 8.065 \times 10^{22} \cdot(\Delta a / a)_{\mathrm{avg}}$ reported for LT-GaAs by Liu et al. [32]. In analogy to LT$\mathrm{GaAs}$, we suppose that $\mathrm{N}\left[\mathrm{As}_{\mathrm{Ga}}^{0}\right]$ monotonically decreases from a maximum value of $\sim 10^{20} \mathrm{~cm}^{-3}$ for as-implanted GaAs : $\mathrm{As}^{+}$ [8] down to the minimum value of about $1 \times 10^{16} \mathrm{~cm}^{-3}$ for the unprocessed SI GaAs substrate [34]. We can then write that $\mathrm{N}\left[\mathrm{As}_{\mathrm{Ga}}^{0}\right] \approx 5.56 \times 10^{22}(\Delta a / a)$ avg for $\mathrm{GaAs}: \mathrm{As}^{+}$. The proportional constant in the expression is of the same order but slightly smaller than that for LT-GaAs. It correlated with the more severely damaged nature of the as-implanted GaAs : $\mathrm{As}^{+}$layer as compared with that of as-grown LT-GaAs. As a result, GaAs: $\mathrm{As}^{+}$must be annealed at a temperature higher than that for LT-GaAs to recover the crystallinity. As a supporting evidence, the concentration, $\mathrm{N}\left[\mathrm{As}_{\mathrm{Ga}}^{0}\right]$ of the GaAs : $\mathrm{As}^{+}$sample annealed at $600^{\circ} \mathrm{C}$ predicted by Fig. 2 was in reasonably good agreement with previously reported value of $\sim 3 \times 10^{18} \mathrm{~cm}^{-3}$ from the capacitance-voltage measurement [35].

The structural parameters, $\Delta a / a$ and $\mathrm{N}\left[\mathrm{As}_{\mathrm{Ga}}^{0}\right]$, of asimplanted and annealed GaAs : $\mathrm{As}^{+}$are summarized in Table I.

\section{B. TEM Analysis}

The cross-section views of the bright field TEM micrographs of as-implanted and furnace-annealed $\mathrm{GaAs} \mathrm{As}^{+}$at $T_{a}=600{ }^{\circ} \mathrm{C}$ are shown in Fig. 3. The as-implanted sample is amorphous and reveals a nonstoichiometric and stress-rich structure. After annealing at $T_{a}=200{ }^{\circ} \mathrm{C}$ for $30 \mathrm{~min}$, the 90 $\mathrm{nm}$-thick implanted layer transformed into the polycrystalline phase with grain boundaries. If $T_{a}$ was increased up to $400{ }^{\circ} \mathrm{C}$, we found that the grain boundaries were almost not discernible. 
TABLE I

\begin{tabular}{|c|c|c|c|c|c|c|c|c|}
\hline & as-implant. & $200^{\circ} \mathrm{C}$ & $300^{\circ} \mathrm{C}$ & $400^{\circ} \mathrm{C}$ & $500^{\circ} \mathrm{C}$ & $600^{\circ} \mathrm{C}$ & $700^{\circ} \mathrm{C}$ & $800^{\circ} \mathrm{C}$ \\
\hline$\left[\mathrm{As}_{\mathrm{Ga}}\right]\left(\mathrm{cm}^{-3}\right)$ & $\cong 1 \mathrm{e} 20$ & $5.9 \mathrm{e} 19$ & $4.5 \mathrm{e} 19$ & $2.2 \mathrm{e} 19$ & $4.8 \mathrm{e} 18$ & $2 \sim 3 \mathrm{e} 18$ & $8.5 \mathrm{e} 17$ & $\sim 2 \mathrm{e} 17$ \\
\hline$I_{\text {dark }}\left(\mathrm{nA} / \mu \mathrm{m}^{2}\right)$ & 12 & $\sim 0.6$ & $\sim 1$ & 0.12 & $8.7 e-5$ & $5.2 \mathrm{e} 5$ & 0.05 & $\sim 3.3$ \\
\hline$\tau(\mathrm{ps})$ & $0.26 \sim 0.3$ & $0.4 \sim 0.42$ & $0.47 \sim 0.5$ & $0.58 \sim 0.6$ & $0.85 \sim 0.9$ & $1.6 \sim 1.9$ & 2.8 & $4.2 \sim 4.6$ \\
\hline$\Delta n\left(\times 10^{-2}\right)$ & $-1.1 \sim-1.3$ & $-0.26 \sim-0.33$ & $-0.1 \sim-0.21$ & $-0.12 \sim-0.18$ & $-0.14 \sim-0.21$ & $-0.27 \sim-0.32$ & $0.6 \sim 0.66$ & $0.85 \sim 0.97$ \\
\hline
\end{tabular}

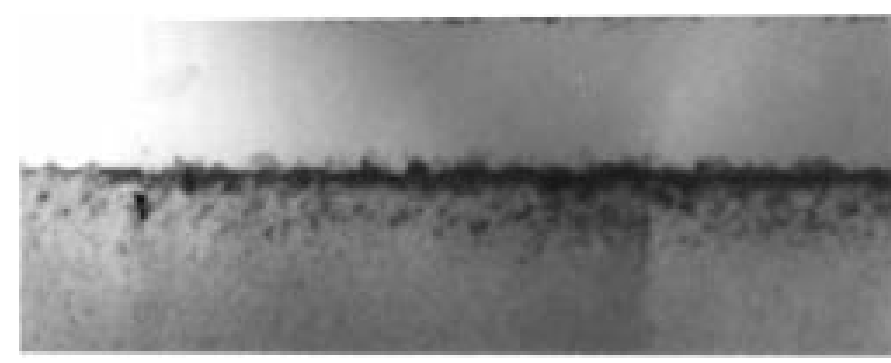

(a)

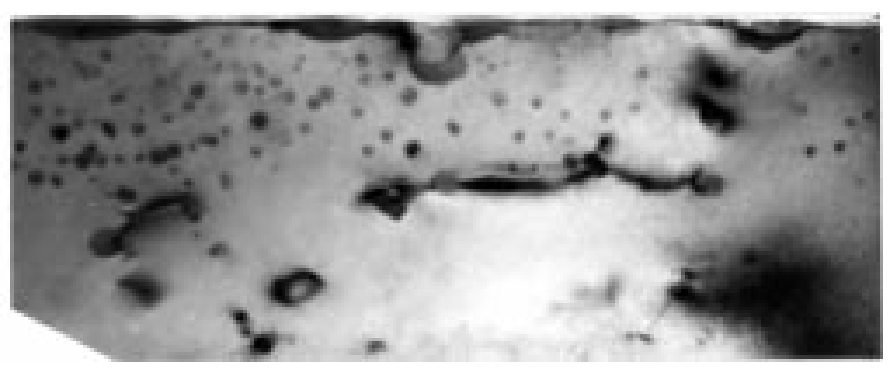

(b)

Fig. 3. The cross-sectional views of the bright-field TEM micrographs and associated electron diffraction patterns of (a) as-implanted and (b) furnace-annealed $\mathrm{GaAs}: \mathrm{As}^{+}$at $T_{a}=600{ }^{\circ} \mathrm{C}$.

The implanted region exhibited a large number of dislocation defects in the GaAs matrix and stacking faults near the surface. No precipitates were observed, however. In comparison, the arsenic precipitating process was found to occur at $T_{a}$ between $400{ }^{\circ} \mathrm{C}$ and $475{ }^{\circ} \mathrm{C}$ for LT-GaAs [28]. For samples annealed at $T_{a}=500{ }^{\circ} \mathrm{C}$, the sample appeared to be single-crystalline in the TEM micrograph. A large number of cluster-type defects, mostly coffee-bean type in shape with a few As precipitates, were observed. The sizes of the precipitates, however, were still beyond the resolution limit of the TEM. The density of clusters was estimated to be $\geq 10^{17} \mathrm{~cm}^{-3}$. For samples annealed at $600{ }^{\circ} \mathrm{C}$, we found the associated (110) diffraction pattern to be perfectly crystalline. Some weak spots in the diffraction pattern also indicate the existence of As precipitates in normal GaAs matrix. The crystal symmetry was assigned as the 3-m rhombohedral As (metallic) group. A significant number of arsenic precipitates and dislocation defects were also observed. The concentration and mean size of arsenic precipitates were about $2 \times 10^{16} \mathrm{~cm}^{-3}$ and 2-3 $\mathrm{nm}$, respectively. In comparison, the concentration and size of As clusters in the LT-GaAs annealed at the same temperature

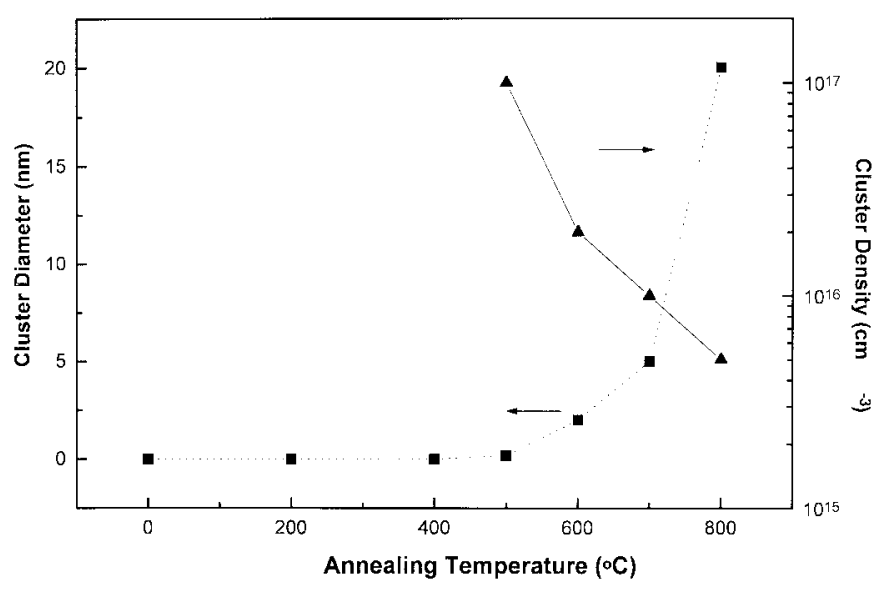

Fig. 4. The diameter and density of arsenic precipitates in GaAs: $\mathrm{As}^{+}$are plotted as a function of annealing temperature.

was reported to be $5 \times 10^{17} \mathrm{~cm}^{-3}$ and 5-8 $\mathrm{nm}$ [36], [37]. $\mathrm{GaAs}: \mathrm{As}^{+}$samples RTA-annealed at $600{ }^{\circ} \mathrm{C}$ for $30 \mathrm{~s}$ were still polycrystalline with a large amount of grain boundaries, dislocation lines, and defects [18]. If the RTA-annealing time was increased from $30 \mathrm{~s}$ up to $10 \mathrm{~min}$ at temperature of $600{ }^{\circ} \mathrm{C}$, the crystal regrowth and arsenic precipitating process become more pronounced [18]. For samples annealed at $T_{a}=$ $700{ }^{\circ} \mathrm{C}$, we observed a large number of precipitates with larger diameters $(\sim 5 \mathrm{~nm})$ and lower density $\left(\sim 1 \times 10^{16}\right.$ $\mathrm{cm}^{-3}$ ) in the bright-field micrographs. Very few dislocation defects were observed. In the electron diffraction pattern of the same sample, we identified less distinct spots superimposed onto the principal diffracted spots. This is interpreted as the manifestation of a decrease in number of As precipitates from the GaAs matrix. Still larger arsenic clusters $(\sim 20$ $\mathrm{nm})$ with further reduced densities $\left(\sim 3 \times 10^{15} \mathrm{~cm}^{-3}\right)$ were observed when the annealing temperature was increased up to $800{ }^{\circ} \mathrm{C}$. The decreasing density may be attributed to both the precipitation into clusters of larger size and the outdiffusion of arsenic ions at high annealing temperatures. Our results illustrate that the arsenic precipitating phenomenon and the fully crystalline regrowth of the implanted region were more pronounced only at higher annealing temperatures. The trends in decreasing concentration but increasing size of As precipitates at higher annealing temperatures are shown in Fig. 4. The size and concentration of the arsenic precipitates as a function of annealing temperature are also summarized in Table $\mathrm{I}$. 


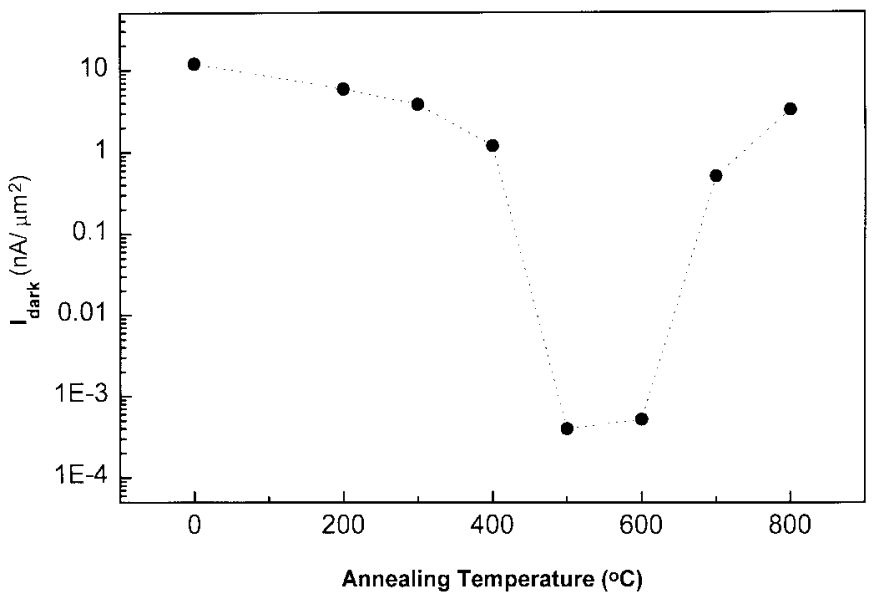

Fig. 5. The dark current densities of Schottky diodes made on the arsenic-ion-implanted GaAs substrates annealed at different temperatures.

\section{Electrical Characteristics}

The leakage current densities, $I_{\text {dark }}$ 's, of Schottky diodes fabricated on $\mathrm{GaAs} \mathrm{As}^{+}$as a function of $T_{a}$ are shown in Fig. 5. The diodes were biased at $-5 \mathrm{~V}$. For example, the leakage current density for the as-implanted sample was -12 $\mathrm{nA} / \mu \mathrm{m}^{2}$. As we increased $T_{a}$ from $200{ }^{\circ} \mathrm{C}$ to $400{ }^{\circ} \mathrm{C}, I_{\text {dark }}$ decreased from -6 to $-1 \mathrm{nA} / \mu \mathrm{m}^{2}$. Following our previous analysis [38], the change from hopping conduction to thermal emission mechanism, corresponding to the decline of density of trapping sites after annealing, is thought to be responsible for the recovery of the resistivity of the damaged surface layer. A reduction of four orders of magnitude of the leakage current from that of the as-implanted sample to a minimum of only about $-3 \times 10^{-4} \mathrm{nA} / \mu \mathrm{m}^{2}$ was observed for samples annealed at $500{ }^{\circ} \mathrm{C}$ and $600{ }^{\circ} \mathrm{C}$. This is attributed to the onset of arsenic precipitation phenomenon presented in Section IV-B. It is consistent with the buried Schottky barrier model proposed by Warren et al. [39]. For $T_{a}>600^{\circ} \mathrm{C}, I_{\text {dark }}$ increased drastically and was as high as $-3.3 \mathrm{nA} / \mathrm{mm}^{2}$ for $\mathrm{GaAs}: \mathrm{As}^{+}$annealed at $T_{a}=800{ }^{\circ} \mathrm{C}$. In Section IV-B, we have also shown that the density of arsenic precipitates decreased as the number of arsenic precipitates in the GaAs matrix dissolved for samples annealed at $T_{a}>600{ }^{\circ} \mathrm{C}$. This behavior is also congruous with the buried Schottky barrier model. It likewise agrees with the work of Claverie et al. [40]. They showed that a large concentration of very small As precipitates were more efficient for increasing the resistivity of arsenic-implanted and furnaceannealed n-type GaAs substrates than a smaller number of larger precipitates. As a result, the implanted layer became more conductive as $T_{a}>600{ }^{\circ} \mathrm{C}$. Furthermore, in our recent work [41], we have identified a shallow acceptor level located at $0.3 \mathrm{eV}$ above the valance band maxima for samples annealed at high temperatures. This level is related to the gallium vacancy (usually denoted as $V_{\mathrm{Ga}}$ )-related defects. These $V_{\mathrm{Ga}^{-}}$ related defects will lead to incomplete compensation between deep donor and shallow acceptor defects. Consequently, the implanted layer becomes more leaky. In view of the elec-

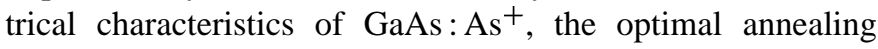
temperature for device applications is between $500{ }^{\circ} \mathrm{C}$ and $600{ }^{\circ} \mathrm{C}$.

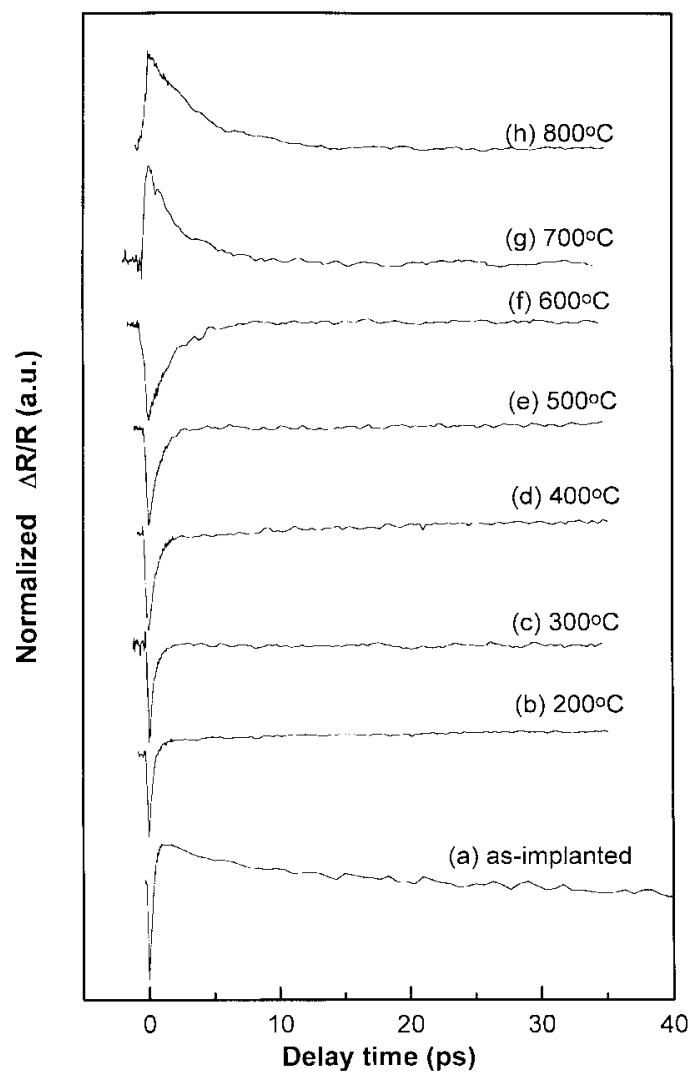

Fig. 6. The normalized time-resolved reflectivity $\Delta R / R$ of the arsenic-ion-implanted GaAs samples annealed at different annealing temperatures.

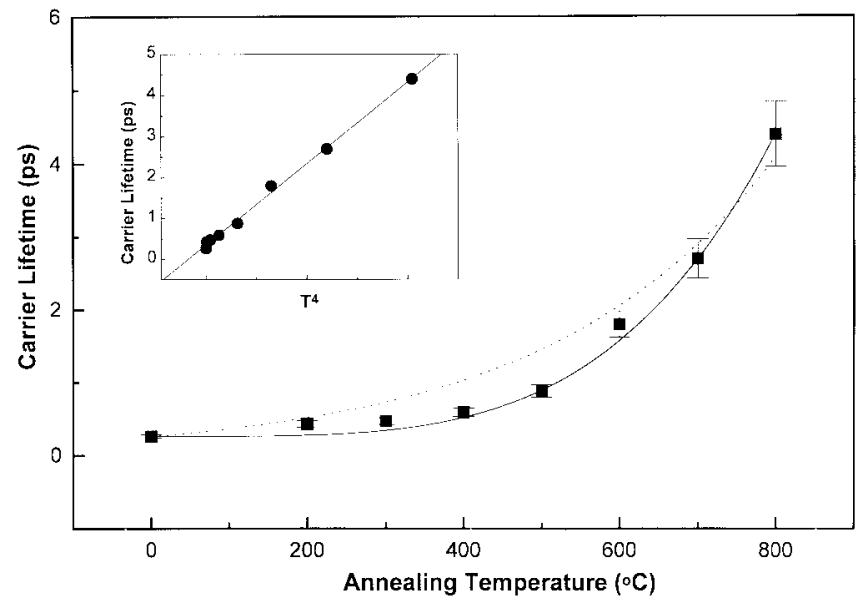

Fig. 7. The photo-excited carrier lifetimes of the arsenic-ion-implanted GaAs samples annealed at different temperatures. The solid and dotted line are fitted curves showing the $T_{a}^{4}$ and exponential dependence (see also the inset which is a semi-log plot).

\section{Ultrafast Optical Properties}

Previously, we have reported subpicosecond photo-excited carrier lifetimes, $\tau_{c}$ 's, ranging from 0.19 to $0.28 \mathrm{ps}$ in GaAs implanted with $200 \mathrm{keV}$ arsenic ions at dosages from $10^{12}$ to $10^{16}$ ions $/ \mathrm{cm}^{2}$ [11]. For RTA-annealed GaAs : $\mathrm{As}^{+}$at 600 to $800^{\circ} \mathrm{C}, \tau_{c}$ 's were observed to lengthen from 0.48 to $2.3 \mathrm{ps}$ [18]. From results of femtosecond time-resolved reflectivity measurements (see Fig. 6) performed in this paper, we find that photo-excited carrier lifetimes of furnace-annealed $\mathrm{GaAs}: \mathrm{As}^{+}$ 


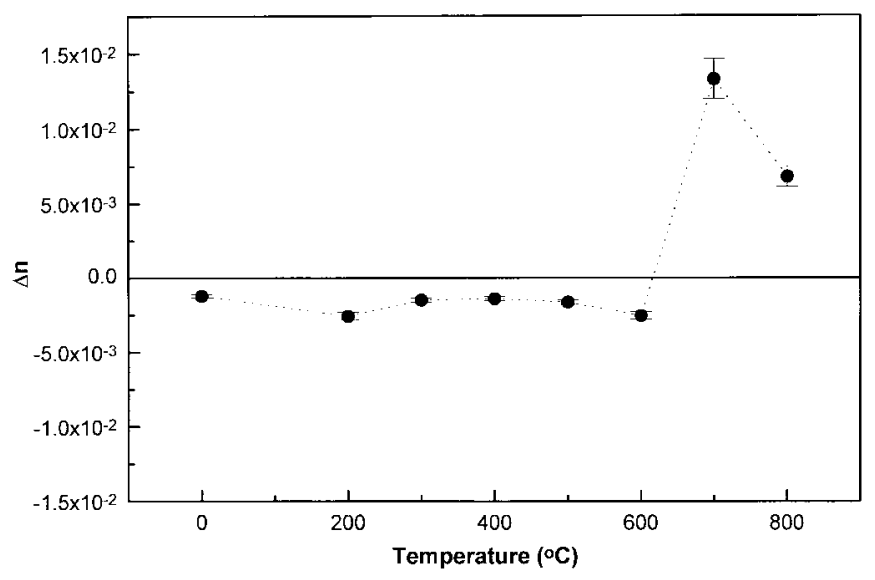

Fig. 8. The peak transient refractive index change $\Delta n$ is plotted as a function of the annealing temperature.

are in the range of $\approx 0.4$ to $4.6 \mathrm{ps}\left(200{ }^{\circ} \mathrm{C} \leq t_{c}\right.$ 's $\left.\leq 800{ }^{\circ} \mathrm{C}\right)$ with an approximate $\left(T_{a}\right)^{4}$ dependence (inset of Fig. 7). The $\tau_{c}$ 's are plotted as a function of $T_{a}$ in Fig. 7. For $T_{a} \leq$ $500{ }^{\circ} \mathrm{C}, \tau_{c}$ 's were found to evolve relatively slowly with increasing $T_{a}$ and were all in the subpicosecond range. The corresponding changes of the refractive index, $\Delta n$, were of the order of -2 to $-3 \times 10^{-3}$. This is shown in Fig. 8 . The maximum $\Delta n$ is comparable with the value reported in previous works on either arsenic-ion-implanted GaAs [42] or MBE grown LT-GaAs materials [43]. A sign reversal for $\Delta n$ was observed for $600{ }^{\circ} \mathrm{C} \leq T_{a} \leq 700{ }^{\circ} \mathrm{C}$. The peak magnitude of $\Delta n$ was as large as 0.01 at $T_{a}=700{ }^{\circ} \mathrm{C}$. This can be explained if the bandgap of GaAs: $\mathrm{As}^{+}$shrinks due to bandgap renormalization toward shorter wavelength after annealing. This picture is in agreement with results of the $\mathrm{CW}$ photoreflectance (CWPR) experiment, as shown in Fig. 9. The signal-to-noise ratio (SNR) of the CWPR data for samples annealed at lower temperatures are relatively poor. This is due to the surface Fermi-level pinning effect, which strongly attenuates the modulated pump signal and the probe beam, reflected from the damaged surface. We observed a blue shift of the CWPR signal for samples annealed at $500{ }^{\circ} \mathrm{C} \leq T_{a} \leq$ $700{ }^{\circ} \mathrm{C}$. This may indicate a recovery on bandgap energy of GaAs: $\mathrm{As}^{+}$samples due to the reduction of defects near the band edge. A sign change of the CWPR amplitude was observed at probe energy of $1.433 \mathrm{eV}$ for samples annealed between $600{ }^{\circ} \mathrm{C}$ and $700{ }^{\circ} \mathrm{C}$. As we have shown in Section $\mathrm{IV}$, the crystallinity of furnace-annealed GaAs : $\mathrm{As}^{+}$recovers approximately after furnace-annealing at $T_{a} \geq 500{ }^{\circ} \mathrm{C}$ for 30 $\mathrm{min}$. Thus the sign reversal in both time-resolved reflectivity and CWPR may be explained by the bandgap shrinkage effect associated with the structural change. At $T_{a}=800{ }^{\circ} \mathrm{C}$, a further sign reversal was observed in the CWPR signal. This may correspond to a type change of the material from n-type to p-type. The reduction of deep-donor defects and the presence of shallow acceptor defects in the samples may explain this result. The CWPR signal at $1.433 \mathrm{eV}$, however, is quite small for the sample annealed at $T_{a}=800{ }^{\circ} \mathrm{C}$ as compared with that of samples annealed at lower temperatures. This is not consistent with the trend for the transient reflectivity signal. Further study is required for clarification.

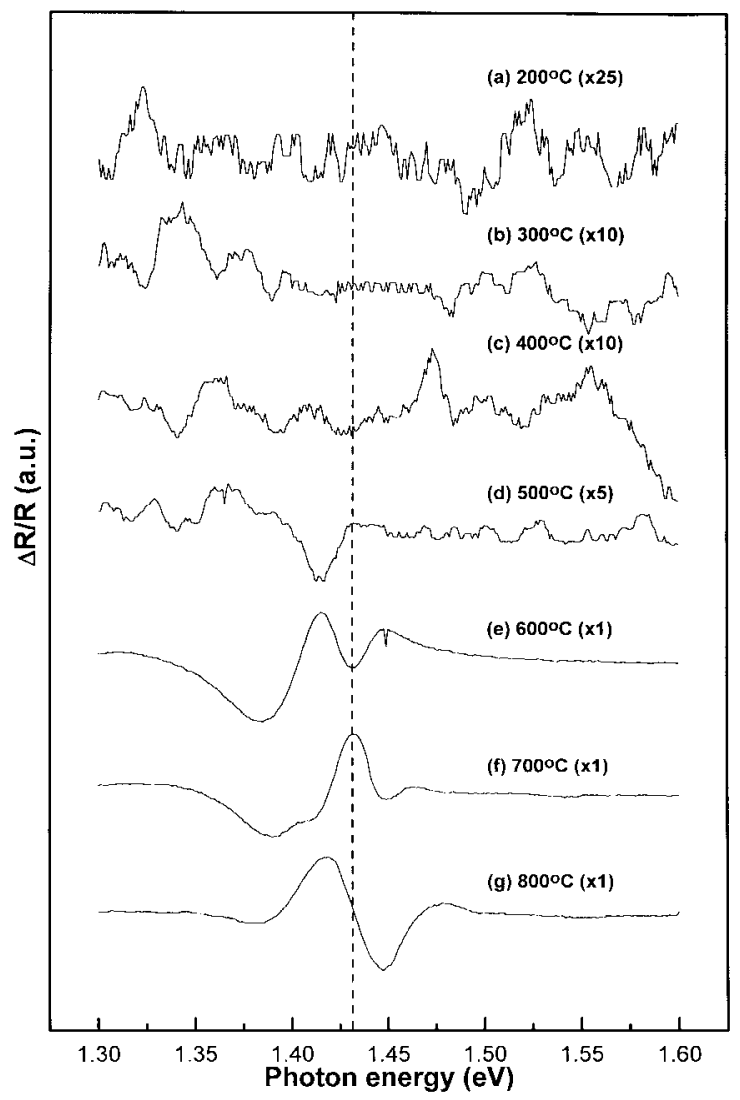

Fig. 9. Results of the CW photoreflectance (CWPR) measurement of GaAs : $\mathrm{As}^{+}$samples annealed at different temperatures. The dashed line shows the pump wavelength for the time-resolved transient reflectivity experiments.

The ultrafast carrier lifetimes are consistent with structural and electrical characterization of $\mathrm{GaAs}^{-\mathrm{As}^{+}}$that demonstrated ultrahigh densities of defects present in the samples. For example, the density of neutral $\mathrm{As}_{\mathrm{Ga}}$ antisite defects remained $\approx 2 \times 10^{17} \mathrm{~cm}^{-3}$ at $T_{a}$ as high as $800^{\circ} \mathrm{C}$. Arsenic precipitates, however, were not observed for $T_{a} \leq 600{ }^{\circ} \mathrm{C}$. This suggests that arsenic clusters were not as important for the ultrafast carrier trapping process in GaAs: $\mathrm{As}^{+}$as for LT-GaAs. We have evaluated the capture cross section of photo-excited carriers in GaAs: $\mathrm{As}^{+}$by using the Shockley-Read-Hall recombination theory [44]. In this model, $t_{c}=\left(N_{t} \sigma v_{t h}\right)^{-1}$, where $N_{t}$ is the concentration of the carrier traps, $\sigma$ is the capture cross section for the photo-excited carriers, and $v_{\text {th }}$ is the thermal velocity of carriers in the photoconductor. We first assumed that $N_{t} \approx \mathrm{N}\left[\mathrm{As}_{\mathrm{Ga}}^{0}\right]$. Using data in Section IV, we find $\sigma \approx 0.2-0.4 \times 10^{-15} \mathrm{~cm}^{2}$ for samples annealed at $T_{a} \leq 400{ }^{\circ} \mathrm{C}$. The cross section increased up to $1-2 \times$ $10^{-14} \mathrm{~cm}^{2}$ for annealing temperatures in the range of 500 ${ }^{\circ} \mathrm{C}-700{ }^{\circ} \mathrm{C}$. At $T_{a}=800{ }^{\circ} \mathrm{C}, \sigma \approx 6-7 \times 10^{-14} \mathrm{~cm}^{2}$, which is at least three times as large as $\sigma$ 's at lower annealing temperatures. To check these values, samples annealed at $600{ }^{\circ} \mathrm{C}$ were also examined by using deep-level transient spectroscopy (DLTS) [36], [39]. Fitting from arrenius plot of the DLTS data, we obtain $\sigma \approx 7 \times 10^{-14} \mathrm{~cm}^{2}$. On the other hand, we can estimate $\sigma$ by using the diameters of the arsenic precipitates. That is, $s \approx \pi d^{2} / 4$. These are $s \approx 2.8 \times 10^{-13}, 2.0 \times 10^{-13}$, and $3.14 \times 10^{-12} \mathrm{~cm}^{2}$, 


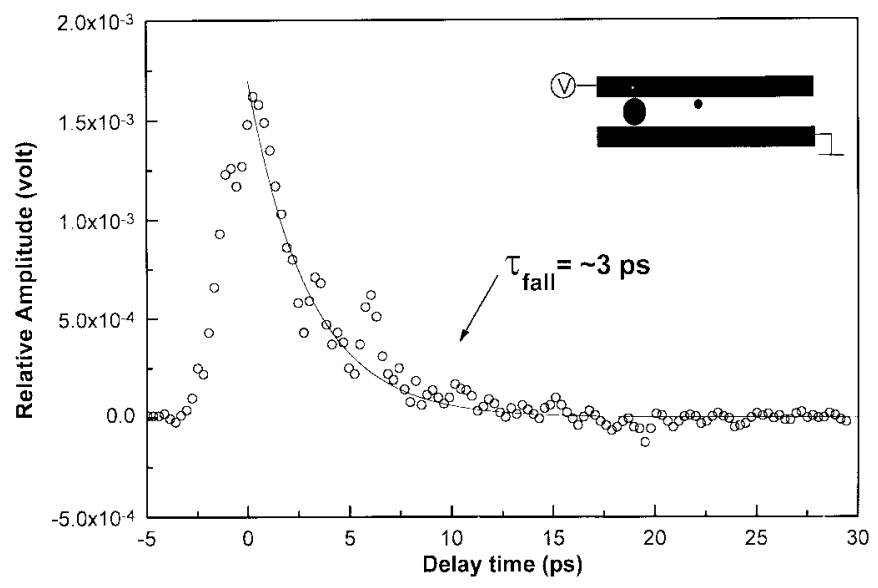

Fig. 10. The electrooptically sampled switching response of a photoconductive switch fabricated on arsenic-ion-implanted GaAs substrate furnace-annealed at $600{ }^{\circ} \mathrm{C}$ for $30 \mathrm{~min}$.

respectively, for $\mathrm{GaAs}: \mathrm{As}^{+}$samples annealed at $T_{a}=$ $600{ }^{\circ} \mathrm{C}, 700{ }^{\circ} \mathrm{C}$, and $800{ }^{\circ} \mathrm{C}$. The corresponding densities of the arsenic precipitates were for the GaAs: $\mathrm{As}^{+}$samples annealed at different temperatures were $N_{\mathrm{As}} \approx 2.0 \times 10^{16}$, $1.0 \times 10^{16}$, and $3.0 \times 10^{15} \mathrm{~cm}^{-3}$, respectively. Accordingly to the Shockley-Read-Hall model, the expected lifetimes would be 5.1, 14.6, and 3.0 ps. These are not in agreement with the experimental data. We conclude that point and structural defects such as the arsenic antisite defects, instead of arsenic precipitates, are dominant as trapping centers of carriers in furnace-annealed GaAs : $\mathrm{As}^{+}$. The capture cross sections and ultrafast optical properties of $\mathrm{GaAs} \mathrm{As}^{+}$are also summarized in Table I.

\section{UltRAFAST OptoElECTRONIC SWITCHING}

From the structural, electrical, and ultrafast optical characterizations of $\mathrm{GaAs}: \mathrm{As}^{+}$in the previous sections, the optimum processing condition for switching applications were determined to be furnace-annealing at $600{ }^{\circ} \mathrm{C}$ and $30 \mathrm{~min}$. A coplanar stripline (CPS) structure with its characteristic impedance of $\sim 75 \Omega$ was fabricated on this material. The 2-cm-long CPS consists of two 30- $\mu$ m-wide transmission lines separated by $15 \mu \mathrm{m}$. The contact metal of the PCS was Au-Ti $(0.5 \mu \mathrm{m}-0.03 \mu \mathrm{m})$. The photoconductively generated electrical pulse as determined by the EEOS system exhibits a pulsewidth of $\sim 4$ ps (FWHM). This is shown in Fig. 10. The risetime and falltime of the impulse response were evaluated to be about 2.2 and 3-4 ps, respectively. These are instrument-limited. Dispersion effect may have broadened the pulse also, as the probe spot was located at $2 \mathrm{~mm}$ from the pump spot. We estimated that the actual response of the PCS to be $\sim 2 \mathrm{ps}$. This is consistent with a $t_{c} \approx 1.8$ ps from transient reflectivity measurement. In comparison, Wang et al. [10] has reported that the response time of the same device fabricated on $\mathrm{GaAs}: \mathrm{As}^{+}$ RTA-annealed at $600^{\circ} \mathrm{C}$ for $15 \mathrm{~s}$ was $\approx 1.23 \mathrm{ps}$ (FWHM). Not long ago, we have also reported that ultrafast switching response of PCS fabricated on low-dosage $\left(10^{13}\right.$ ions $\left./ \mathrm{cm}^{2}\right)$ implanted $\mathrm{GaAs}: \mathrm{As}^{+}$substrate. The switching response of
RTA- and furnace-annealed low-dose-implanted PCS were $\sim 3$ and $8 \mathrm{ps}$, respectively [17].

The dark current of an Auston-type GaAs : As ${ }^{+}$PCS with a gap size of $30 \mu \mathrm{m}$ fabricated on the same substrate was measured to be as low as $15 \mathrm{nA}$ under a bias voltage of $40 \mathrm{~V}$. The corresponding electric field biased across the gap is higher than $150 \mathrm{kV} / \mathrm{cm}$. Such low dark current indicates that the annealed sample can sustain much higher bias voltage before breakdown. In comparison, the dark currents of PCS's fabricated on SI GaAs and RTA-annealed GaAs: $\mathrm{As}^{+}$were $>10 \mathrm{nA}$ and $\approx 100 \mu \mathrm{A}$ at the same bias.

With a bias voltage of $20 \mathrm{~V}$, the responsivity of the PCS operated in $\mathrm{CW}$ and pulse mode were $0.004 \mathrm{~A} / \mathrm{W}$ and $\geq 0.03$ $\mathrm{A} / \mathrm{W}$, respectively. The injected optical average powers were $100 \mathrm{~mW}$ (pulse mode) and $3 \mathrm{~mW}$ (CW mode), respectively. The responsivity is somewhat larger than the value of the devices made on different materials such as LT-GaAs $(\sim 0.001$ A/W) [45]. The higher responsivity may be attributed to the contribution from the GaAs substrate since the thickness of the implanted layer was too thin to absorb the injected photons entirely.

\section{CONCLUSION}

We have performed extensive structural, electrical, ultrafast optical, and optoelectronic characterization of furnaceannealed $\mathrm{GaAs}: \mathrm{As}^{+}$. Structurally, we find the as-implanted GaAs: $\mathrm{As}^{+}$to be amorphous. The crystallinity of the implanted region fully recovers for $T_{a} \geq 500{ }^{\circ} \mathrm{C}$. Arsenic precipitating process is observed for $T_{a} \geq 500{ }^{\circ} \mathrm{C}$ only. Instead, arsenic antisite defects, $\mathrm{As}_{\mathrm{Ga}}$, are shown to be the dominant carrier trap for carriers for $T_{a}$ as high as $800{ }^{\circ} \mathrm{C}$. The trap densities are evaluated from the strain data and shown to decrease from $10^{20}$ for the as-implanted sample to $\sim 2 \times$ $10^{17} \mathrm{~cm}^{-3}$ at $800{ }^{\circ} \mathrm{C}$. Increasing the annealing temperature from $T_{a}=400{ }^{\circ} \mathrm{C}$ to $500{ }^{\circ} \mathrm{C}$, the dark current densities of the samples decrease drastically by two orders of magnitude to $\approx 3 \times 10^{-4} \mathrm{nA} / \mathrm{mm}^{2}$. A sharp rise in $I_{\mathrm{dc}}$ was then observed for $T_{a} \geq 700{ }^{\circ} \mathrm{C}$. This is explained in terms of the density and size of the average As precipitates for samples annealed at different $T_{a}$ 's. The photo-excited carrier lifetimes are found to evolve slowly but remain subpicosecond in samples annealed at $200{ }^{\circ} \mathrm{C} \leq T_{a} \leq 500{ }^{\circ} \mathrm{C}$. The $\tau_{c}$ 's then rise distinctly to $4.6 \mathrm{ps}$ as $T_{a}$ is increased to $800^{\circ} \mathrm{C}$ with an approximately $T_{a}^{4}$ dependence. If we assumed that $\mathrm{As}_{\mathrm{Ga}}$ was the dominant trap, the capture cross sections of the deep-level trapping centers in furnace-annealed GaAs: $\mathrm{As}^{+}$are in agreement with the Shockley-Read-Hall model and estimated to be in the range of $0.2-6 \times 10^{-14} \mathrm{~cm}^{2}$. The transient change in refractive indices is of the same order as those of annealed LT-GaAs. The $\Delta n$ is as large as 0.01 for GaAs : $\mathrm{As}^{+}$furnace-annealed at $T_{a} \geq 600$ ${ }^{\circ} \mathrm{C}$. A sign reversal in $D n$ is observed at this temperature. We have tentatively attributed this phenomenon to the bandgap shrinkage effect. From the above studies, we have determined that GaAs substrate implanted with $200-\mathrm{keV}$ arsenic ions at $10^{16}$ ions $/ \mathrm{cm}^{2}$ and furnace-annealed at $500{ }^{\circ} \mathrm{C}-600{ }^{\circ} \mathrm{C}$ for 30 min would have recovered its crystallinity, be highly resistive, and exhibit picosecond photo-excited carrier lifetimes. Indeed, switching responses as fast as 3-4 ps (instrument limited) were 
realized for coplanar-stripline type PCS's fabricated on the above material. We estimated the actual response to be $\approx 2$ ps, consistent with a photo-excited carrier lifetime of $\approx 1.8$ ps. The peak responsivity was $\geq 4 \times 10^{-3} \mathrm{~A} / \mathrm{W}$. The dark current for the GaAs: $\mathrm{As}^{+}$PCS biased at $40 \mathrm{~V}$ was as low as $5 \mathrm{nA}$. The breakdown field was higher than $150 \mathrm{kV} / \mathrm{cm}$. These characteristics are comparable to those of state-of-theart photoconductors such as LT-GaAs. We thus conclude that the furnace-annealed $\mathrm{GaAs}: \mathrm{As}^{+}$is an attractive alternative to LT-GaAs for ultrafast optoelectronic applications.

\section{ACKNOWLEDGMENT}

The authors would like to thank Prof. C.-H. Lee of the University of Maryland, on sabbatical at NCTU, for informative and helpful discussions. Technical support by Prof. K.-F. Hwang, Dr. Feruz Ganikhanov, and the National Nanoscale Devices Laboratory (NDL) is appreciated.

\section{REFERENCES}

[1] D. H. Auston, "Picosecond photoconductivity: High-speed measurements of devices and materials," in Semiconductors and Semimetals, R. B. Marcuse, Ed. San Diego, CA: Academic, 1990, vol. 28, pp. 85-130.

[2] M. B. Johnson, T. C. McGill, and N. G. Paulter, "Carrier lifetimes in ion-damaged GaAs," Appl. Phys. Lett., vol. 54, pp. 2424-2426, 1989.

[3] A. Esser, W. Kutt, M. Strahnen, G. Maidorn, and H. Kurz, "Femtosecond transient reflectivity measurements as a probe for process-induced defects in silicon," Appl. Surf. Sci., vol. 46, pp. 446-450, 1990.

[4] T. Pfeiffer, J. Kuhl, E. O. Gobel, and L. Palmetshofer, "Temperature dependence of the picosecond carrier relaxation in silicon-irradiated silicon-on-sapphire films," J. Appl. Phys., vol. 62, pp. 1850-1855, 1987.

[5] F. E. Donaey, D. Grischkowsky, and C.-C. Chi, "Carrier lifetime versus ion-implantation dose in silicon on sapphire," Appl. Phys. Lett., vol. 50, pp. 460-462, 1987

[6] F. W. Smith, H. Q. Le, V. Dradiuk, M. A. Hollis, A. R. Calawa, S Gupta, M. Frankel, D. R. Dykaar, G. A. Mourou, and T. Y. Hsiang, "Picosecond GaAs based photoconductive optoelectronic detectors," Appl. Phys. Lett., vol. 54, pp. 890-892, 1989.

[7] A. Claverie, F. Namavar, and Z. Liliental-Weber, "Formation of As precipitates in GaAs by ion implantation and thermal annealing," Appl. Phys. Lett., vol. 62, pp. 1271-1273, 1993.

[8] G.-R. Lin, W.-C. Chen, C.-S. Chang, and C.-L. Pan, "Electrical characterization of arsenic-ion-implanted semi-insulating GaAs by currentvoltage measurement," Appl. Phys. Lett., vol. 65, pp. 3272-3274, 1994.

[9] H. Fujioka, J. Krueger, A. Prasad, X. Liu, E. R. Weber, and A. K. Verma, "Annealing dynamics of arsenic-rich GaAs formed by ion implantation," J. Appl. Phys., vol. 78, pp. 1470-1476, 1995.

[10] H. H. Wang, J. F. Whitaker, H. Fujioka, and Z. Lilienthal-Weber, "Ultrafast electronics and optoelectronics," in OSA Technical Digest Series. Washington, DC: Opt. Soc. Amer., 1995, vol. 13, pp. 32-34.

[11] F. Ganikhanov, G.-R. Lin, W.-C. Chen, C.-S. Chang, and C.-L. Pan, "Subpicosecond carrier lifetime in arsenic-ion-implanted GaAs," Appl. Phys. Lett., vol. 67, pp. 3465-3467, 1995.

[12] A. Krotkus, S. Marcinkevicius, J. Jasinski, M. Kaminska, H. H. Tan, and C. Jagadish, "Picosecond carrier lifetime in GaAs implanted with high doses of As ions: An alternative material to low-temperature GaAs for optoelectronic applications," Appl. Phys. Lett., vol. 66, pp. 3304-3306, 1995.

[13] A. Claverie, F. Namavar, and Z. Liliental-Weber, "Formation of As precipitates in GaAs by ion implantation and thermal annealing," Appl. Phys. Lett., vol. 62, pp. 1271-1273, 1993.

[14] M. Kaminska, E. R. Weber, Z. Liliental-Weber, R. Leon, and Z. U. Rek, "Stoichiometry-related defects in GaAs grown by molecular-beam epitaxy at low temperatures," J. Vac. Sci. Technol. B, vol. 4, pp. 710-713, 1989.

[15] D. C. Look, D. C. Walters, M. O. Manasreh, J. R. Sizelove, and C E. Stutz, "Anomalous Hall-effect results in low-temperature molecularbeam-epitaxy GaAs: Hopping in a dense EL2-like band," Phys. Rev. B, vol. 42, pp. 3578-3581, 1990 .

[16] H.-H. Wang, P. Grenier, J. F. Whitaker, H. Fujioka, J. Jasinski, and Z. Liliental-Weber, “ Ultrafast response of As-implanted GaAs photocon- ductors," IEEE J. Select. Topics Quantum Electron., vol. 2, pp. 630-635, 1997.

[17] G.-R. Lin and C.-L. Pan, "Picosecond responses of low-dosage arsenicion-implanted GaAs phoconductors," Appl. Phys. Lett., vol. 71, pp. 2901-2903, 1997.

[18] G.-R. Lin, W.-C. Chen, F. Ganikhanov, C.-S. Chang, and C.L. Pan, "Effect of rapid thermal annealing on carrier lifetimes of arsenic-ion-implanted GaAs," Appl. Phys. Lett., vol. 69, pp. 996-998, 1996.

[19] A. Esser, W. Kutt, M. Strahnen, G. Maidorn, and H. Kurz, "Femtosecond transient reflectivity measurements as a probe for process-induced defects in Silicon," Appl. Surf. Sci., vol. 46, pp. 446-450, 1990.

[20] W. T. Stacy and M. M. Janssen, J. Cryst. Growth, vol. 27, p. 282, 1974

[21] V. Swaminathan and A. T. Macrander, Materials Aspects of GaAs and InP Based Structures. Englewood Cliffs, NJ: Prentie-Hall, PrenticeHall Advanced Reference Series, 1991.

[22] V. S. Speriosu, B. M. Paine, M.-A. Nicolet, and H. L. Glass, "X-ray rocking curve study of Si-implanted GaAs, Si, and Ge," Appl. Phys. Lett., vol. 40, pp. 604-606, 1982.

[23] G. T. Brown, S. J. Barnett, S. J. Courtney, and S. S. Gill, "A study of the distribution of hydrogen and strain in proton-bombarded liquid-encapsulated Czochralski-grown GaAs by double-crystal X-ray diffraction and secondary ion mass spectrometry," Mater. Sci. Eng. B, vol. 2, pp. 91-97, 1989.

[24] M. Fatemi, P. E. Thompson, J. Chaudhuri, and S. Shah, "Double crystal X-ray analysis of strain distribution in rapid thermal annealed, S-implanted GaAs," J. Appl. Phys., vol. 68, pp. 3964-3969, 1990.

[25] H. Fujioka, J. Krueger, A. Prasad, X. Liu, E. R. Weber, and A. K. Verma, "Annealing dynamics of arsenic-rich GaAs formed by ion-implantation," J. Appl. Phys., vol. 78, pp. 1470-1475, 1995.

[26] B. M. Kaminska, Z. Liliental-Weber, E. R. Weber, T. George, J. B. Kortright, F. W. Smith, B-Y. Tsaur, and A. R. Calawa, "Structural properties of As-rich GaAS grown by molecular beam epitaxy at low temperatures," Appl. Phys. Lett., vol. 54, pp. 1881-1883, 1989.

[27] M. Fatemi, B. Tadayon, M. E. Twigg, and H. B. Dietrich, "Highresolution x-ray analysis in low-temperature GaAs," Phys. Rev. B, vol. 48, pp. 8911-8917, 1993.

[28] Z. Liliental-Weber, K. M. Yu, Washburn, and Look, "Anomalies of annealed LT-GaAs samples,” J. Electron. Mater., vol. 22, pp. 1395-1399, 1993.

[29] J. Gebauer, R. Krause-Rehberg, S. Eichler, M. Luysberg, H. Sohn, and E. R. Weber, "Ga Vacancies in low-temperature-grown GaAs identified by slow positrons," Appl. Phys. Lett., vol. 71, pp. 638-640, 1997.

[30] M. H. Chan, S. K. So, K. T. Chan, and F. G. Kellert, "Defect density measurements of low temperature grown molecular beam epitaxial GaAs by photothermal deflection spectroscopy," Appl. Phys. Lett., vol. 67, pp. 834-836, 1995.

[31] M. O. Manaresh, D. C. Look, K. R. Evans, and C. E. Stutz, "Infrared absorption of deep defects in molecular-beam-epitaxial GaAs layers grown at $200{ }^{\circ} \mathrm{C}$ : Observation of an EL2-like defect," Phys. Rev. B, vol. 41, pp. 10272-10275, 1990

[32] X. Liu, A. Prasad, S. Nishio, E. R. Weber, Z. Liliental-Weber, and W. Walukiewicz, "Native point defects in low-temperature-grown GaAs," Appl. Phys. Lett., vol. 67, pp. 279-281, 1995.

[33] J. Jasinski, Z. Liliental-Weber, J. Washburn, H. H. Tan, C. Jagadish, A Krotkus, S. Marcinkevicius, and M. Kaminska, "Structural, electrical, and optical studies of GaAs implanted with $\mathrm{MeV}$ As or Ga Ions," $J$. Electron. Mater., vol. 26, pp. 449-458, 1997.

[34] C.-L. Pan, H.-H. Wu, and T.-R. Hsieh, "Near-infrared transmission measurement of EL2 concentration in semi-insulating GaAs wafer with laser diode $(\lambda=1.3 \mu \mathrm{m})$," Jpn. J. Appl. Phys., vol. 30, pt. 1, pp. 1430-1432, 1991.

[35] W.-C. Chen and C.-S. Chang, "Effect of thermal annealing on electrical conductivities in arsenic-ion-implanted GaAs," Appl. Phys. Lett., vol. 68, pp. 646-648, 1996.

[36] Z. Liliental-Weber, X. W. Lin, J. Washburn, and W. Schaff, "Rapid thermal annealing of low-temperature GaAs layers," Appl. Phys. Lett., vol. 66, pp. 2086-2088, 1995 .

[37] Z. Liliental-Weber, K. Yu, J. Washburn, and D. C. Look, "Anomalies in annealed LT-GaAs samples," J. Electron. Mater, vol. 22, pp. 1395-1399, 1993.

[38] W.-C. Chen, G.-R. Lin, and C.-S. Chang, "The dynamics of thermal annealing in arsenic-ion-implanted semi-insulating GaAs," Jpn. J. Appl. Phys., vol. 35, pt. 2, pp. L192-L194, 1996.

[39] A. C. Warren, J. M. Woodle, J. L. Freeouf, D. Grischkowsky, and M. R. Melloch, "Arsenic precipitates and the semi-insulating properties of GaAs buffer layers grown by low-temperature molecular beam epitaxy," Appl. Phys. Lett., vol. 57, pp. 1331-1333, 1990. 
[40] A. Claverie, H. Fujioka, L. Laanab, Z. Liliental-Weber, and E. R. Weber, "Synthesis of semi-insulating GaAs by As implantation and thermal annealing: Structural and electrical properties," Nucl. Instrum. Methods Phys. Res. B, vol. 96, pp. 327-330, 1995.

[41] W.-C. Chen and C.-S. Chang, "Electrical properties in arsenic-ionimplanted GaAs," J. Appl. Phys., vol. 80, pp. 1600-1604, 1996.

[42] S. Janz, U. G. Akano, and I. V. Mitchell, "Nonlinear optical response of the $\mathrm{As}^{+}$-ion implanted GaAs studied using time-resolved reflectivity," Appl. Phys. Lett., vol. 68, pp. 3287-3289, 1996.

[43] S. D. Benjamin, A. Othonos, and P. W. E. Smith, "Large ultrafast nonlinearities in As-rich GaAs," Electron. Lett., vol. 30, pp. 1704-1706, 1994.

[44] S. Wang, Fundamentals of Semiconductor Theory and Device Physics. Englewood Cliffs, NJ: Prentice-Hall, Prentice Hall Advanced Reference Series, 1989, pp. 277-283.

[45] M. Y. Frankel, J. F. Whitaker, G. A. Mourou, F. W. Smith, and A. R. Calawa, "High-voltage picosecond photoconductor switch based on low-temperature-grown GaAs," IEEE Trans. Electron Devices, vol. 37, pp. 2493-2497, 1990.

Gong-Ru Lin (S'92-M'97), photograph and biography not available at the time of publication.

Wen-Chung Chen, photograph and biography not available at the time of publication.

C.-S. Chang, photograph and biography not available at the time of publication.
Shyh-Chin Chao, photograph and biography not available at the time of publication.

Kaung-Hsiung Wu, photograph and biography not available at the time of publication.

T. M. Hsu, photograph and biography not available at the time of publication.

W. C. Lee, photograph and biography not available at the time of publication.

Ci-Ling Pan (M'88), photograph and biography not available at the time of publication. 